\title{
A civilização escolar pelos compêndios didáticos de formação de professores
}

\section{The school civilization by the didactic compendia of teacher training}

\author{
Carlota Boto*
}

\begin{abstract}
RESUMO
O presente trabalho tem por finalidade averiguar aspectos concernentes ao cotidiano escolar por sua dimensão ritual. A hipótese da educação escolar como rito de iniciação será o foco norteador da pesquisa. Nesse sentido, os documentos trabalhados foram variados, contemplando fundamentalmente, para os casos de Portugal e do Brasil, livros didáticos de formação de professores. Quando se observam os modos de ensino, constata-se a força da estatura cultural da escola. Se a disposição de um sistema de ensino codifica normas de agir para a estrutura da rede escolar, há aspectos, no domínio da escola, que extrapolam as prescrições normativas dos programas oficiais e das diretrizes que contam como ou o quê se deverá ensinar. Portanto, é possível dizer que nem tudo que a escola faz estava previsto para que ela o fizesse. Os compêndios dirigidos à escola primária e à formação de professores, em sua dimensão histórica, são, por óbvio, reveladores de um dado processo psíquico civilizador. Nesses, a palavra é dirigida à regulação de comportamentos.
\end{abstract}

Palavras-chave: História da Educação. Livros didáticos. Ensino. Cultura escolar. Didática.

\footnotetext{
ABSTRACT

The present work has the purpose of ascertaining aspects concerning the school routine, due to its ritual dimension. The hypothesis of school education as a rite of initiation is the guiding focus of this research. In this sense, various documents were studied, contemplating mainly, for the cases in Portugal and Brazil, didactic books of teacher training. By observing the

* Universidade de São Paulo. Faculdade de Educação. São Paulo, São Paulo, Brasil. E-mail: reisboto@usp.br. https://orcid.org/0000-0002-7389-2391.
} 
modes of teaching, one can verify the strength of the cultural stature of the school. If the provision of an educational system encodes rules of action for the structure of the school network, there are aspects in this field that go beyond the normative prescriptions of the official programs and guidelines that tell how or what to teach. In this regard, it is possible to say that not everything that the school does can be predicted. The compendia addressed to primary school and teacher training are, in their historical dimension, clearly revealing a given psychic process of civilization. The word there is directed to the regulation of behaviors.

Keywords: History of Education. Didactic books. Teaching. School culture. Didacticism.

O presente trabalho tem por finalidade averiguar aspectos próprios ao cotidiano escolar, por sua dimensão ritual. A hipótese da educação escolar como rito de iniciação será o foco norteador da pesquisa. Nesse sentido, os documentos trabalhados foram variados, contemplando fundamentalmente, para os casos de Portugal e do Brasil, livros didáticos de formação de professores.

Quando se observam os modos de ensino, constata-se a força da estatura cultural da escola. Se a disposição de um sistema de ensino codifica normas de agir para a estrutura da rede escolar, há aspectos, no domínio da escola, que extrapolam as prescrições normativas dos programas oficiais e das diretrizes que contam como ou o quê se deverá ensinar (AZANHA, 1990/1991, 1992). Nesse sentido, é possível dizer que nem tudo que a escola faz estava previsto que ela o fizesse. Por esse motivo - como adverte Azanha - de nada adiantará descrever as condutas e modos de agir das escolas pelos "objetivos que a norma legal lhes prescreve" (1990/1991, p. 66). A escola não poderá ser avaliada sem que se mergulhe na lógica inscrita em sua vida cotidiana. Se práticas escolares são normatizadas em um conhecimento teórico, para além dessa mesma teoria, existem artes e atitudes especificamente escolares, por meio das quais a instituição veicula valores, saberes e protocolos de comportamento.

As relações sociais escolares são, ainda, relativamente autônomas frente a outras instâncias da sociedade. A escola moderna tem a homogeneidade como princípio, como método e como propósito declarado. Historicamente, as práticas pedagógicas destacam-se - pelo menos desde o século XIX - pelas características de simultaneidade e uniformidade constitutivas dos ritos escolares. Tais requisitos foram imprescindíveis para conformar a instituição formadora. A escola de Estado dispõe-se, na vida em sociedade, a falar sobre certos assuntos com o fito de criar um repertório comum das crianças, passível de se estabelecer como o repertório comum da nação. A escola primária configura-se, por 
tal perspectiva, como instituição voltada para padronizar costumes e projetar saberes. Apresenta como impessoais, universais e atemporais as regras de que se vale. Como sublinha Norbert Elias, trata de racionalizar, institucionalizar e tornar interdependentes os costumes (ELIAS, 1993, 1994); de tal maneira que à infância sejam ensinados os padrões de pudor, de vergonha e de autocontrole; os quais, por suposto, deveriam regular o comportamento adulto (POSTMAN, 1999).

Popkewitz sublinha a necessidade de se engendrar uma "epistemologia social da escolarização" (POPKEWITZ, 2001, p. 152), em virtude exatamente da invenção da categoria aluno. Esta confere novo significado bem como altera a representação do próprio conceito de "criança como objeto do escrutínio do professor" (POPKEWITZ, 2001, p. 155). É necessário considerar, quando se pensa nas representações sociais decorrentes da escolarização, os modos pelos quais os saberes científicos se inscrevem nos livros didáticos, as estratégias por meio das quais os protocolos societários são apreendidos pelos professores e as maneiras pelas quais os alunos se apropriam desses saberes, desses valores, dessas normas de ação. A cultura como mundo construído que surge também na escola abarca, a um só tempo, a apropriação dos conteúdos que circulam na sociedade e a criação de novos saberes, interiores à vida escolar. O rito de escola é, nesse sentido, também sua transgressão. Onde há norma, há resistência. Há conflito. Há sempre os que buscarão burlar a regra. E há, ainda, os que desconhecem a regra. De todo modo, a escola como rito deverá ensinar e recordar as normas e as regras de vida coletiva, até para ensaiar com as gerações novas o rito da vida em coletividades. A escola traz - pode-se dizer - a segunda socialização da criança. Ela preparará, por isso, a futura vida social. Dentro dela, há o aprendizado dos preceitos que deverão regular a sociabilidade. Daí ser fundamental que a instituição atente também para os possíveis fatores de resistência, de recusa, de transgressão. A vida dos adultos se dispõe a partir de certos códigos; e esses códigos precisarão ser aprendidos.

Existe - pode-se dizer - uma singular dimensão simbólica concernente ao âmbito cultural da escolarização - dimensão simbólica que dialoga muito de perto com comunidades de sentido autorizadas, partilhadas, no tecido social. Cria-se - nessa perspectiva - uma distinta apreciação do tempo e uma nova distribuição do espaço. O tempo escolar ganha vida como repertório de significados inscritos, por sua vez, no espaço da escola, em sua territorialidade. Estrutura-se, portanto, uma linguagem própria, que tende a representar a instituição como sua vertente autorizada. A modernidade engendrou uma maneira específica de ser e de viver a escola. Essa escola, construída e mantida pela modernidade, configura-se como instituição inscrita em uma "arquitetura" de tempos, de espaços e de ritos (VIÑAO FRAGO, 1998a, 1998b). Nesse sentido, 
“forma escolar" (VINCENT, 1980, 1994), "modelo escolar" (NÓVOA, 1987, 1991, 1994, 1995, 1998, 2001), “cultura(s) escolar(es)" (JULIA, 2001; VIDAL, 2005) e "gramática da escola moderna" (TYACK; CUBAN, 1995), todos esses registros implicam significados concernentes à especificidade desse protocolo da escolarização (PARO, 2011, p. 490).

A escola - em sua institucionalização - forma o autodomínio e este, em tese, gera o bem comum. A escola cumpre missão civilizadora (SOUZA, 1998). Daí a necessidade de formar hábitos que tornem bem comportada a meninice. A instituição escolar, dentre outras coisas, serve também para isso. Há crianças bem-comportadas; e há aquelas que precisarão aprender a sê-lo. Os meninos que chegam aos bancos escolares serão os novos selvagens. Por tal razão, é compreensível que sejam, à partida, sonsos, matreiros, preguiçosos, distraídos, atrevidos. Mas precisarão perder os maus costumes. Precisarão se tornar civilizados. As crianças que não se comportam bem nas escolas, todavia, não têm necessariamente a intenção de transgredir. Elas simplesmente desconhecem os códigos do comportamento prescrito. Há uma fronteira clara entre os modos tolerados de comportamento fora e dentro da escola. A circunscrição do espaço, a cerimônia do gestual, a repetição diária dos ritos, tudo isso compõe um novo mundo a ser apreendido. Esse será, talvez, o primeiro aprendizado a ser feito na escola: o aprendizado da própria liturgia da escolaridade.

O modelo da escolarização moderna, a "forma escolar de socialização" para utilizar a expressão de Guy Vincent $(1980,1994)$ - na gramática que lhe é peculiar (TYACK; CUBAN, 1995) - constitui um projeto civilizatório. O campo teórico que vem se constituindo como "cultura(s) escolar(es)" (JULIA, 2001; VIDAL, 2005) busca identificar, nessa medida, a conjunção entre os saberes e fazeres produzidos internamente no âmbito cultural da escolarização e as representações sociais que, fora da escola, são sobre ela produzidas. Assim como a escola - mediante uma cultura que ela própria irá produzir - cria e recria seu próprio repertório de saberes, é possível verificar que ela, além disso, fará uma apropriação do conhecimento científico que pretende transpor para a ação de ensinar. Pode-se por isso dizer que, no interior da escola, são conscientemente mobilizados preceitos e roteiros de comportamento que terão como propósito o desenvolvimento de um ethos civilizatório que é exterior ao próprio lugar público ocupado pela escola.

Norbert Elias compreende, como processo psíquico interpessoal, a ação que identifica como artifício civilizador das sociedades ocidentais. Procurando diferenciar etimologicamente o conceito latino de civilização com seu possível equivalente, o termo alemão kultur, ele observa que são maneiras distintas de se pensar o problema. À palavra latina civilitas, teria recebido correspondentes em várias línguas: "a francesa civilité, a inglesa civility, a italiana civilità e a 
alemã zivilltät. Civilizar é produzir a transformação integral do ser interior do homem a partir de modificações no comportamento exterior: aquele que cuida da "postura, dos gestos, do vestuário, das expressões faciais" (ELIAS, 1994, p. 69).

Haveria - considera Elias - uma distinção primordial especificamente entre os conceitos francês e inglês voltados para abordagem desse universo da produção inteligente de significados sociais. Enquanto a ideia de kultur alemã expressa, acima de tudo, a marca de seu lugar de tradição, denotando um povo e suas criações, a ideia de civilização indica um movimento. Tal procedimento é, em primeiro lugar, prescritivo de um roteiro, que não é particular ou individual deste ou daquele povo. Trata-se de um percurso universal; e se não é, compreende-se que deveria sê-lo. O conceito de civilização assume um dado caminho como se ele fosse o único. Sendo assim, supõe-se que os povos deverão ter similaridade na assunção desse movimento tendencial, independentemente de sua história nacional, de suas experiências compartilhadas, de seus usos e costumes ou de sua vocação regional. Já o conceito de kultur valoriza as identidades, o pluralismo, as particularidades das diferentes culturas como sinais possíveis de caminhos diversos na trilha de suas histórias. Elias verifica a principal diferença entre civilização e cultura, considerados seus lugares originários de produção.

A civilização é ensinada sempre simultaneamente à produção de seus próprios códigos. Não existiria, de antemão, um plano racional e deliberado para que a sociedade (ou as camadas dominantes dessa sociedade) decidisse traçar um prospecto de longa duração com o propósito de controlar o desempenho das pessoas. Não se trata, todavia, de um percurso ao acaso.

Os compêndios dirigidos à escola primária e à formação de professores são, por óbvio, reveladores de tal "processo psíquico civilizador" (ELIAS, 1994, p. 14). A palavra ali é dirigida à regulação de comportamentos, especificando critérios de tudo o que a "sociedade exige e proíbe" (ELIAS, 1994, p. 14).

Chagas de Carvalho indica as maneiras pelas quais se poderá identificar uma pedagogia inscrita nas próprias lógicas de organização dos materiais escolares, especialmente nos impressos de uso didático. Qualquer trabalho que se proponha a integrar o que a autora qualifica de "história cultural dos saberes pedagógicos" (CARVALHO, 2001, p. 138) deverá buscar compreender as "regras que constituem o campo, os objetos e os objetivos da intervenção escolar, incidindo também sobre os processos de produção, difusão e apropriação da multiplicidade de impressos de destinação pedagógica" (CARVALHO, 2001, p. 138). Essa "dimensão normativa dos discursos pedagógicos", prossegue Carvalho, incide diretamente na maneira pela qual os saberes veiculados pelos impressos serão apropriados por seus leitores, professores e alunos. Nesse sentido, pode-se encontrar um âmbito prescritivo nos manuais pedagógicos que, ao 
circularem, contribuem para divulgar representações intrínsecas aos "conteúdos teóricos ou doutrinários da pedagogia" (CARVALHO, 2001, p. 138).

Vivian Batista da Silva destaca que "os manuais fundaram determinados discursos sobre o ensino, traduzindo-os e dando-os a ler" (SILVA, 2011, p. 310). Foram eles, diz ela, que deram voz a discursos dos grandes autores da pedagogia. Ou seja: em geral, é por meio dos manuais - sob a ênfase deste ou daquele trecho, desta ou daquela ênfase - que os grandes clássicos do discurso pedagógico são interpretados. Ao se apropriar dos clássicos, considera Silva (2011), não se estaria, porém, efetuando uma mera repetição. Conforme a autora, "nesses textos, as ideias originais foram selecionadas, retomadas com outras palavras, seguiram uma lógica de explicação diferente" (SILVA, 2011, p. 310).

Trabalhando agora a documentação escolhida, temos a obra de Feliciano Bittencourt, particularmente seu Compêndio de pedagogia escolar. Na edição de 1908, há uma clara preocupação em tornar ternos e amenos os rituais do aprendizado do aluno. Haverá uma preleção que norteará o cerimonial da aula. Por seu turno, essa explicação que dá o tom do ritual escolar será dirigida pelo conteúdo do livro. O livro, portanto, ensina ao professor as coisas que ele deverá transmitir em sua explanação. Além disso, o ensino deverá, pois, ter a explicação sempre matizada pelo exemplo. $O$ exemplo faculta a compreensão, ao mesmo tempo em que propicia a repetição, necessária para a memória. $\mathrm{O}$ professor deverá explicar com linguagem simples os pontos da matéria sobre a qual se debruça, sem se preocupar excessivamente com os termos utilizados pelo livro didático.

As explicações serão sempre acompanhadas de múltiplos exemplos, bem adequados ao assunto da lição, de modo a tornar-se de fácil compreensão. Um processo que dá seguros resultados é o seguinte: fazer o professor com que o aluno leia em voz alta o assunto da lição que tem de ser estudada; e, no fim de cada frase ou parágrafo, ordenar que um outro repita o que foi lido, com o livro fechado. E se, por acaso, o texto não for suficientemente compreendido, cumpre-lhe reduzir a matéria a termos simples, familiares, de sorte a não restarem dúvidas no espírito da criança. (BITTENCOURT, 1908, p. 174-175).

Quando lemos uma passagem como essa, invariavelmente indagamos: esse roteiro de ações aqui prescritas indicava o que deveria ser feito em sala de aula ou revelava o que os professores já faziam na época? Creio que podemos dizer que, em alguma medida, ambas as situações são contempladas: de fato, há uma nítida e explícita dimensão prescritiva, com o texto expondo argumentos 
para evidenciar a superioridade dessa maneira de fazer as coisas em sala de aula; por outro lado, é plausível supor que a prescrição contenha em si também o elemento da experiência bem-sucedida. Muito provavelmente, portanto, esse ritual já era presente em alguma sala de aula. E, mesmo para nós, ele não parece exatamente desconhecido.

O mesmo autor compreende que os rituais da escola primária são diretamente decorrentes da estrutura física da escola, que deverá contar com um acervo material que possibilite a existência de aulas, tais como - por suposto - elas deveriam ser. Todas as escolas primárias, por exemplo, precisarão dispor de "um estrado sobre o qual repousa a mesa do mestre; bancos-carteiras em número suficiente; um quadro-negro; giz e esponja; quadros para aprendizagem da leitura; um quadro do sistema métrico; cartas geográficas e o mapa-múndi”" (BITTENCOURT, 1908, p. 140). Além disso, deveria existir também um armário para servir de biblioteca. Nesse sentido, pode-se dizer que Bittencourt reforça a hipótese de Marta Carvalho (2001, 2006) e Margarida Louro Felgueiras (2010), cujas análises concluem que a cultura material da escola é um relevante fator de apreensão das coisas que efetivamente se passam nas salas de aula. Para Marta Carvalho, os materiais utilizados para o ensino estão intrinsecamente vinculados aos métodos, aos modos de ensinar e à própria pedagogia; o que, por sua vez, incita ao domínio de práticas atreladas estas "à materialidade dos objetos que lhes servem de suporte. As práticas que se formalizam nos usos desses materiais guardam forte relação com uma pedagogia em que tal arte é normatizada como boa imitação de um modelo" (CARVALHO, 2006, p. 147).

Também os materiais individuais dos alunos serão elementos fundamentais para descortinar o ritual da sala de aula.

Todos os alunos do curso primário elementar devem possuir o seguinte: caderno para exercícios escritos; uma ardósia; um primeiro livro de leitura. Os do curso médio igualmente um caderno para exercícios diários; um livro de leitura corrente, de acordo com o programa do curso; uma gramática elementar com exercícios; uma aritmética também elementar, um pequeno atlas de geografia e um resumo de história pátria. Os do curso complementar estudarão as mesmas disciplinas com maior desenvolvimento e mais a história geral e a instrução geral e cívica (BITTENCOURT, 1908, p. 140-141).

Augusto Coelho - autor português cuja obra é bastante utilizada em escolas normais portuguesas e brasileiras do início do século XX (CARVALHO, 
2001, 2006) - já assinalava a importância de se pensar a dinâmica da disciplina escolar, organizada como esteio para o desenvolvimento das qualidades da vontade. Em Noções de pedagogia elementar, obra cuja $2^{\mathrm{a}}$ edição foi publicada em Lisboa, em 1907, J. Augusto Coelho advoga a tese de que o fator prioritário do capítulo concernente à disciplina escolar seria o de formar a criança para a constância de bons hábitos, adquiridos pela boa educação e capazes de firmar nos estudantes a educação da vontade. Para o pedagogo, "na educação da vontade, os dois objetivos fundamentais do professor são exaltar a energia mental dos alunos e formar-lhe o caráter" (COELHO, 1907, p. 68). Educar a vontade, sob tal perspectiva, corresponde a disciplinar os impulsos e a levar o estudante a "conformar o seu querer com as leis e regras destinadas a conduzi-lo, quer, em geral, a respeitar os princípios da ordem, quer, em especial, a aplicar a atenção ao estudo" (COELHO, 1907, p. 70). Tenciona-se, no limite, forjar a vontade autônoma por meio do hábito bem preparado. $\mathrm{O}$ autor recorda que, para conseguir isso, o professor deverá - para apresentação das noções - valer-se da clareza, da distinção e da viveza, "pois embalde tentará conciliar a atenção dos outros quem for obscuro, confuso e arrastado" (COELHO, 1907, p. 70). Trata-se, pois, de instar o aluno a se modificar, no que for necessário, sem, para tanto, valer-se da "imposição regulativa de prescrições" (COELHO, 1907, p. 72). O caráter se forma quando os esforços incidem sobre a persistência e sobre a constância das ações; numa palavra, sobre a formação dos hábitos.

Como teóricos da "ciência que trata da educação" (COELHO, 1907, p. 234), os educadores precisam possuir três características. Além de "espírito enciclopédico" (COELHO, 1907, p. 235), eles precisam ter "percepção apta a distinguir, numa dada noção, o essencial do acidental, o fundamental do acessório; qualidades de precisão e clareza; tendência ordenadora e coordenadora" (COELHO, 1907, p. 235). Por seu turno, os professores, na qualidade de "aplicadores práticos" (COELHO, 1907, p. 235) da pedagogia, precisarão desenvolver alguns atributos - todos eles concernentes a seu modo de se comportar em sala de aula. No trato com as crianças, o mestre deverá ser paciente e benevolente capaz de angariar a simpatia e o afeto de seus alunos. Moralmente, é necessário que suas ações primem pela justiça e pela coerência entre o necessário rigor e a imprescindível brandura e suavidade necessária ao papel de educador. Finalmente, ele, professor, deverá se comportar de maneira a se tornar um exemplo para seus alunos. Nas palavras de Coelho:

Pelo lado intelectual, ter noções claras acerca das condições exteriores destinadas a modificar o aluno em harmonia com o fim em vista, isto é, acerca do instrumento educativo, da maneira de aplicar a sua ação ao 
educando e da ordem em que deve ser aplicada; pelo lado emocional, tendência para se emocionarem perante as fraquezas da personalidade alheia, isto é, a simpatia e, portanto, lhaneza, doçura, suavidade, benevolência, afetuosidade, etc.; pelo lado moral, uma estrutura moral capaz de servir de exemplo ao educando, no ditar os fins e os meios: clareza na objetivação e coerência na maneira de conceber esses meios e fins nas diversas situações da vida, quando dirigirem o educando na aplicação dos meios aos fins - bom senso nas coações, suavidade e brandura sem prejuízo da sua eficácia - entre o próprio proceder moral e o proceder ditado ao aluno, rigorosa conformidade naquilo que possa ser possível. (COELHO, 1907, p. 235).

Em seu Manual Pratico de Pedagogia para uso dos professores em geral e em especial dos professores de ensino médio e primário, Augusto Coelho descreve, com bastante nitidez, os procedimentos mediante os quais de deverá proceder o que o autor compreende por ordem pedagógica. Na verdade, o ritual escolar está claramente contido nessa expressão: "dispor numa certa ordem" (COELHO, s.d., p. 155) os objetos de ensino, de modo a que o método venha a se desdobrar da prescrição geral para o caso-exemplo particular. Esse método - tal como indicava já o tratado de Comenius - deveria "seguir do homogêneo para o heterogêneo, avançar do obscuro, confuso e indefinido para o claro, distinto e definido; partir do conhecido para o desconhecido" (COELHO, s.d., p. 155).

Para dar conta de um bom plano de trabalho e para executar na plenitude seu lugar na liturgia escolar, o professor precisará ter algumas aptidões intelectuais e algumas disposições morais, já que "um professor sem vida, arrastado, sonolento convida quantos o ouvem ao adormecimento e à apatia" (COELHO, s.d., p. 176). É preciso, pelo contrário, que ele saiba prender a atenção pode seus atos, que ele "prenda às suas palavras todas as atenções, atraia pela sua exposição todos os espíritos" (COELHO, s.d., p. 176).

Com habilidade para apresentar a matéria com clareza e distinção, o professor precisará também ter uma "animação proporcionada à natureza do objeto de ensino" (COELHO, s.d., p. 177). Outras qualidades do professor dão exata noção do que o autor compreendia como sendo o tom do ritual da aula. Nesse sentido, além da "posse plena do objeto de ensino" (COELHO, s.d., p. 176), será imprescindível ao professor possuir tanto o espírito de análise para delimitar e decompor os objetos em seus elementos e o espírito de síntese para recompor os objetos - à guisa de recapitulação. Assim, a teoria, decomposta, é retomada. Por isso mesmo, na lógica ritual requerida pela ordenação escolar, caberá ao professor: 
Um certo equilíbrio entre estas duas aptidões, quer para não se perder mercê de uma análise exagerada, em minúcias inúteis, quer para não se abalançar - mercê d'uma síntese precipitada, a unificações mal preparadas. Em relação ao método de ensino: a) espírito bem acentuado de ordenação pedagógica para, numa mesma série, se lhe disporem no mais natural e lógico encadeamento os diversos objetos de ensino; b) espírito bem ponderado de coordenação, a fim de estabelecer uma racional convergência dos objetos de ensino pertencentes a séries ou disciplinas diversas para com o objeto especial de que tratar, sem contudo se diluir por aqueles a atenção do aluno em tanta demasia que este fique prejudicado. (COELHO, s.d., p.176-177).

Antes da publicação da obra de Augusto Coelho, já Camilo Passalaqua, em livro intitulado Pedagogia e Methodologia - publicado em São Paulo no ano de 1887 -, indica os caracteres que deverão estar presentes no professor, procurando articulá-los com os princípios a serem observados relativamente aos alunos. Kulesza (2011, p. 562) destaca que o livro de Passalaqua - que teria sido bastante usado nas Escolas Normais brasileiras desde sua primeira edição - constitui um tratado de pedagogia. Em Pedagogia e Methodologia, há o entendimento claro de que cabe à didática a tarefa de "investigar e demonstrar os princípios reguladores do mestre que ensina, do aluno que aprende e do próprio ensino que se há de dar" (PASSALAQUA, 1887, p. 147-148). Sob tal aspecto, o autor identifica tais princípios dizendo que "ninguém deve ensinar se não tiver zelo, gosto e conhecimento da matéria" (PASSALAQUA, 1887, p. 148), além de capacidade de expressão. Mas ninguém deverá ensinar principalmente se não tiver crença no progresso de seus alunos. Por seu turno, "o aluno deve ter vontade de instruir-se e disposição para o estudo" (PASSALAQUA, 1887, p. 148). Deve também se habituar a falar corretamente o português. Finalmente, os princípios relativos ao ensino são divididos quanto ao conteúdo - racional, prático, moral e religioso - e quanto à forma. Os princípios relativos à forma do ensino retomam a perspectiva de Herbart sobre o tema: analítico, sintético, lento e engendrado mediante sucessivas recapitulações da matéria ministrada. Como demonstra o trabalho de Rita de Cássia Gallego, não se pode dizer que aquilo que consta dos manuais ou mesmo das prescrições do ensino ministrado fosse a expressão transparente e acabada do relato das práticas ${ }^{1}$. As práticas são, todavia, sempre "móveis" (CHARTIER, 1990, p. 78). Justamente por isso,

1 "Ainda que se indicasse no manual que era dever o oferecimento de um modelo de distribuição do tempo e do trabalho para o método simultâneo e o misto, não era localizado, entre os materiais aos quais se teve acesso, qualquer modelo nesse sentido." (GALLEGO, 2008, p. 287). 
talvez houvesse já um dado modelo, expresso como "roteiro metodológico" (AZANHA, 1992; CARVALHO, 2001, 2006), a partir do qual a orientação viesse a se processar. E era esse o roteiro que dava a baliza dos próprios livros sobre a arte de ensinar.

Em Portugal, publicando na cidade de Coimbra a 6 a edição de sua obra Elementos de Pedagogia, António Leitão destaca, de maneira próxima aos autores acima referidos, os atributos necessários ao ser professor: hábil, consciencioso, fisicamente robusto, disciplinado, dedicado e conhecedor de seu ofício e das matérias a serem ensinadas. Mais do que tudo isso, o profissional do ensino deve primar pelo "tato pedagógico" (LEITÃO, 1916, p. 32). Esse imprescindível requisito o "leva a conhecer sem esforço as necessidades do ensino, o grau de energia intelectual e moral dos seus alunos e os professos a empregar com o modo de ser psíquico próprio de cada um deles" (LEITÃO, 1916, p. 32). A forma do ensino recomendada para a organização das aulas respeitaria, por seu turno, a ideia de o professor desenvolver uma lição, com a possibilidade de o aluno ir fazendo perguntas ao longo da preleção do mestre. Para que as aulas não se tornassem rituais monótonos, enfadonhos e infrutíferos, com longas explicações, sugeria-se dinamizar o processo do ensino, com o recurso à palavra do aluno - que poderia interrogar e ser também a qualquer momento interrogado. Para o ritual da escola se processar, havia de se ter em conta, todavia, os recursos materiais ou utensílios necessários para a vida da sala de aula. Para qualquer tipo de relação de ensino obter êxito, considera-se fundamental:

a) o quadro preto, auxiliar quase constante do ensino oral; b) o livro, guia do professor e elementos de recapitulação para o aluno; c) os exercícios escritos, destinados a verificar melhor o aproveitamento do aluno, a apurar as suas faculdades de síntese e a dar ao professor um descanso relativo no meio do incessante trabalho da direção de uma escola. (LEITÃO, 1916, p. 45).

O aluno, por sua vez, terá seu caráter formado pela conformação de seu corpo e de seu espírito a uma criteriosa disciplina escolar. A disciplina, para Leitão, implica ordem, esforço e boa vontade do aluno para colaborar com o trabalho do professor e na atenção. Só assim a inteligência do aluno poderá se focar e se concentrar "e assim a sua inteligência aplica-se e concentra-se sobre o objeto das lições, aprende mais prontamente o que o professor explica e desenvolve-se gradualmente, ao mesmo tempo em que adquire uma soma maior de conhecimentos" (LEITÃO, 1916, p. 49). Para adquirir a estima e a confiança 
dos alunos, não deverá o professor ser irascível ou de constante mau humor. Por outro lado, se os alunos quebrarem o elo da confiança e se tornarem excessivamente rebeldes, além de poderem ser admoestados ou reprimidos, poderão ter "a privação de recreio, detenção na escola depois de findos os exercícios escolares, ou quaisquer outros castigos paternalmente aplicados" (LEITÃO, 1916, p. 52).

Mesmo assim, o rito da escola, além disso, ou se isso não for suficiente, deverá comportar prêmios e castigos. Os primeiros poderão se traduzir em um elogio oral público, na concessão para algum aluno de uma função distintiva que a classe toda almeje cada um para si ou mesmo uma "inscrição no quadro das menções honrosas" (AFFREIXO; FREIRE, 1879, p. 29). Já os castigos podem consistir na repreensão individual ou pública, na inscrição do nome do aluno infrator no quadro negro, como forma de registro de sua má conduta e até de uma exclusão - temporária ou definitiva (esta em último caso). A orientação, sobre o tema, é bastante explícita: "a honra mancha-se com as más ações praticadas; logo é justo que o aluno, que, depois de ser inscrito no quadro de honra, desmereceu da boa conta em que fôra tido, lhe seja riscado o nome" (AFFREIXO; FREIRE, 1879, p. 30). Para que não fosse perpetuado qualquer tipo de estigma, se o aluno se emendar de seus erros, tenha seu nome eliminado "do quadro dos que mal praticam. Tornou-se bom? Vá mais tarde ao quadro de honra" (AFFREIXO; FREIRE, 1879, p. 30).

Parece interessante observar a letra do que diz o texto, mas, por detrás dela, o espírito de sua diretriz. Boa parte do que se dizia sobre os castigos ou sobre a criação de estigmas, muito provavelmente viria em consonância com práticas realmente existentes nas escolas primárias daquela época. Note-se que o compêndio não recomenda o castigo corporal, identificado como "uma das mais tristes persuasões que constitui o extremo recurso das ínfimas camadas populares" (AFFREIXO; FREIRE, 1879, p. 31). A revolução escolar deverá ser operada pela persuasão; e só por meio desta ela poderá ser desejada. O castigo físico - embora fosse, como se sabe, uma prática bastante em uso nas escolas portuguesas daquele tempo -, recomenda-se que seja abolido do território pedagógico ${ }^{2}$.

2 Mas o ritual indicado para as aulas não se resume ao comportamento moral. Era necessário refletir sobre o que deveria ser ensinado e sobre a ordem pela qual esse ensino se processa. O livro de Affreixo e Freire expõe, por exemplo, o que o professor primário deveria ensinar em Aritmética: "I. Ideia de quantidade, de unidade e número; II. Número inteiro decimal e misto; III. Ideia de frações; IV. Leitura e escrita de números; V. Quatro operações de inteiros e decimais; VI. Problemas de uso comum; VII. Redução à unidade; VIII. Regra de três. Em todo o ensino é necessário ter a ideia de utilidade; neste, porém, não pode haver o mínimo descuido à precisão da linguagem e do cálculo. Trate também o professor de sempre fazer com que seus alunos resolvam o maior número de problemas de uso comum; será esta a parte mais profícua do seu ensino de aritmética" (AFFREIXO; FREIRE, 1879, p. 63). 
É possível pensar a educação como estratégia para cumprimento da predestinação humana? Seria a educação escolar uma forma de conduzir as crianças a perfazerem um destino que lhes teria sido previamente traçado? O que determina as possibilidades de formação humana? Como lidar contra as adversidades do meio e da biologia para se obter êxito na tarefa educativa? Haveria a possibilidade de assegurar estratégias que, se bem observadas, auxiliassem a ensinar bem? Quais os segredos da construção da boa aula? Se são essas as indagações que movem boa parte desses compêndios, também é bastante comum a identificação da ideia de aula como lição coletiva, a partir da qual será estruturado o momento dos exercícios, até porque "na escola deve haver cuidado de que o aluno trabalhe sempre" (AFFREIXO; FREIRE, 1879, p. 48).

O método é compreendido como ordenamento do processo do ensino, de modo a que se possa organizar a ordem ritual pela qual se processará o trabalho com cada matéria. Os saberes são, assim, dispostos em fila, em um roteiro que classifica prioridades e sequências didáticas; e, por meio das estratégias e técnicas adotadas, são engolfados pelas lições e exercícios. Nesse sentido, a repetição das palavras, dos gestos e das atividades gerará ritos, cuja regularidade cotidiana engendra o modo de ser da sala de aula. Os ritos, desse modo, traduzir-se-ão como uma forma específica de se lidar com o tempo e com o espaço. É como se, pela ritualidade, houvesse a interrupção do contínuo do tempo para se engendrar o lugar de um novo tempo, aquele do transcurso da ritualização. A escola como o rito retira a criança, portanto, de suas pertenças familiares e comunitárias, porque instaura, para ela, uma temporalidade nova - e necessária para seu desempenho institucional. Por aí é que se pode considerar a existência do ritual da escola primária.

Manoel Bomfim - professor da Escola Normal do Rio de Janeiro, diretor do Pedagogium e diretor do Laboratório de Psicologia Experimental - oferecerá uma definição conclusiva em seu livro Lições de Pedagogia: theoria e pratica da educação (1920): o conceito de pedagogia como um campo teórico de organização do conhecimento científico aplicado à educação. Para o autor, pedagogia é a sistematização dos princípios científicos como uma forma estruturada de organizar a racionalidade dos métodos e procedimentos da intervenção educativa. Destarte, a pedagogia dispõe sobre o concerto ritual da escolarização. Esse rito será também, de acordo com os autores aqui encadeados, um cerimonial de apresentação de matérias: umas após as outras, em sequências fixas e hierarquicamente definidas. Haverá "cientificamente" uma ordem de exposição dos conteúdos de ensino, e essa ordem é antes pedagógica do que epistemológica. A pedagogia torna-se, sob tal compreensão, a ciência que dispõe as matérias do mundo em ordem para poderem ser mais facilmente 
assimiladas e compreendidas. Mais do que isso, é também a arte de formar bons hábitos e atitudes conforme regras.

Os manuais didáticos, compondo-se como guias para direção da sala de aula, em suas práticas e suas rotinas, precisarão ser, pelo uso, traduzidos como atividades de classe, transformados em roteiros didáticos de ensino da leitura e da escrita. Esse processo, por si próprio, exigirá (especialmente para o caso das disciplinas escolares) algum nível de transposição didática; mediante a qual os saberes teóricos serão subordinados a finalidades pedagógicas - o que supõe uma adequação dos mesmos conteúdos aos níveis de cognição dos alunos, a partir das fases específicas de seu desenvolvimento físico, mental e emocional. Vera Valdemarin observa essa intrincada relação entre os conteúdos escolares e as especificidades da condição dos alunos. Para a autora:

O saber escolar está, então, intimamente ligado à atividade de construir significados assimiláveis pelo aluno, fazendo uso da razão, do raciocínio normalizado, organizando o conhecimento numa sequência compreensível pautada por exercícios que visem a estimular e fixar a aprendizagem, tendo por objetivo a manutenção da cultura e da sociedade. [...] entre as transformações sofridas pelos saberes científicos ou eruditos em saberes a serem ensinados, congregando paradigmas epistemológicos e selecionando-os segundo critérios sociais e econômicos nem sempre explicitados. A explicitação desses critérios pode ser delineada no diálogo com o contexto histórico no qual emergem as elaborações filosóficas e didáticas, ou seja, da discussão sobre o papel desempenhado pela escola na formação de tipos específicos de raciocínio derivados de conteúdos também determinados. (VALDEMARIN, 2004, p. 132).

Joaquim Pintassilgo já observou que os manuais de formação de professores do século XIX e princípio do XX caracterizam a pedagogia simultaneamente como "ciência da educação" e como "arte de ensinar". A ideia é de que se trata de uma "ciência aplicada" (PINTASSILGO, 2011, p. 202). Para o autor, há nitidamente a valorização da "dimensão artesanal do trabalho docente" (PINTASSILGO, 2011, p. 207). Diz Pintassilgo que "tanto a vocação como a paixão surgem como metáforas de um ensino assente em valores e em propósitos morais, de um professor crente em ideais remetendo para o aperfeiçoamento humano, de um comprometimento simultaneamente racional e emotivo e de um exercício da profissão criativo e desafiador" (PINTASSILGO, 2011, p. 207). Por ser assim, ao ensinar, esse artista da profissão deverá trabalhar simultânea e necessariamente o aprendizado de saberes, valores e costumes. 
Retomar o entrelaçamento da história com a filosofia da educação pode se constituir como recurso compreensivo para se obter elementos passíveis de reconstituir a trança - entre práticas efetivamente engendradas nos diferentes rituais que diferentes escolas perfilham, em suas similaridades e diferenças - e os traços do pensamento pedagógico que prescreve modos e maneiras de se dar aula, recomendando esta ou aquela por esta ou aquela razão. Reconstituir a história das práticas de ensino paralelamente à busca de compreensão das teorias pedagógicas é uma maneira de se buscar apreender quais práticas foram as que mais "deram certo", quais foram bem-sucedidas. Aí, então, nós teremos mais elementos para, porventura, compreender: por que esta ou aquela escola, este ou aquele professor ensinam bem ou ensinam mal? Quais são as formas de ensinar mais merecedoras de crédito por seus méritos, por seus resultados e por seu reconhecimento público? Quais são os ritos que precisarão ser abolidos do cenário de sala de aula? Ao buscar no passado aspectos capazes de interagir com os problemas do nosso "tempo presente" - como historiadores - poderemos retomar a fertilidade de uma história do pensamento educacional que não seja cindida do estudo das condições materiais do ensino de sua época. Não se trata de elaborar o que já foi denunciado como "sínteses desencarnadas". Mas pensar algumas das intersecções entre o pensamento pedagógico e as realidades concretas das escolas constitui, em meu entendimento, um desafio colocado para as novas gerações. De fato, se a escola inventa seus modos de ser e de agir, se os ritos ali produzidos são cerimônias e protocolos internos, pode-se, mesmo assim, considerar que essa invenção tem a baliza de algumas referências: referências teóricas, conceituais e de método. Como pensar os estilos pelos quais se processou o ensino nas diferentes tradições nacionais, regionais, locais, em um mundo em constante deslocamento? As novas tecnologias da informação, bem como as modificações no cenário migratório e demográfico acarretam inusitadas problemáticas para projetarmos os temas da história da educação. $\mathrm{O}$ processo de mundialização da economia trará consigo a pretensão de uniformizar práticas e reinstalar rituais? Como articular a tradição da escola moderna com as novas demandas da sociedade digital se todo o formato da escola ainda é tributário da cultura do livro impresso? Trata-se, sob quaisquer hipóteses, de investigar, sistematizar e divulgar os movimentos e deslocamentos pelos quais ritos e tradições escolares são constituídos. 


\section{REFERÊNCIAS}

AZANHA, J. M. P. Cultura escolar brasileira: um programa de pesquisas. Revista USP: dossiê educação, n. 8, p. 65-69, dez./fev. 1990/1991.

AZANHA, J. M. P. Uma idéia de pesquisa educacional. São Paulo: EDUSP, 1992.

CARVALHO, M. M. C. A caixa de utensílios e a biblioteca: pedagogia e práticas de leitura. In: VIDAL, D. G.; HILSDORF, M. L. S. (Orgs.) Brasil 500 anos: tópicas de história da educação. São Paulo: Edusp, 2001. p. 137-167.

CARVALHO, M. M. C. Chagas. Livros e revistas para professores: configuração material do impresso e circulação internacional de modelos pedagógicos. In: PINTASSILGO, J.; CARVALHO, M. M. C.; FREITAS, M. C.; MOGARRO, M. J. (Orgs.). História da Escola em Portugal e no Brasil. Circulação e apropriação de modelos culturais. Lisboa: Colibri/Centro de Investigação em Educação da Faculdade de Ciências da Universidade de Lisboa, 2006. p. 141-173.

CHARTIER, R. A história cultural: entre práticas e representações. Lisboa: Difel, 1990.

ELIAS, N. O processo civilizador. volume 2. Rio de Janeiro: Zahar, 1993.

ELIAS, N. O processo civilizador. volume 1. Rio de Janeiro: Zahar, 1994.

FELGUEIRAS, M. L. Cultura escolar: da migração do conceito à sua objetivação histórica. In: FELGUEIRAS, M. L.; VIEIRA, C. E. (Orgs.). Cultura escolar, migrações e cidadania. Porto: Sociedade Portuguesa de Ciências da Educação, 2010. p. 17-32.

JULIA, D. A cultura escolar como objeto histórico. Revista Brasileira de História da educação, SBHE - Sociedade Brasileira de História da educação, Campinas, ano 1, n. 1, p. 9-43, 2001.

KULESZA, W. A. Desarrollo de los manuales pedagógicos em Brasil (1870-1940). In: PERANDOLES, P. C. (Ed.). Arte y oficio de enseñar: COLOQUIO NACIONAL DE HISTORIA DE LA EDUCACIÓN, 16., 2011. vol. I. El Burgo de Osma: Universidad de Valladolid/Sociedad Española de Historia de la Educación, 2011. p. 557-566.

NÓVOA, A. Le temps des professeurs. Volumes I e II. Lisboa: Imprensa Nacional, 1987.

NÓVOA, A. Para o estudo sócio-histórico da gênese e desenvolvimento da profissão docente. Teoria e Educação, 4, 1991.

NÓVOA, A. História da educação. Faculdade de Psicologia e Ciências da Educação/ Universidade de Lisboa: [mimeografado], 1994.

NÓVOA, A. Profissão professor. Porto: Porto Editora, 1995.

NÓVOA, A. Histoire \& comparaison. Lisboa: Educa, 1998. 
NÓVOA, A. Texts, images and memories: writing New Histories of Education. In: POPKEWITZ, T. S.; PEREYRA, M. A.; FRANKLIN, B. M. Cultural history and education. New York: Routlegdefalmer, 2001. p. 45-66.

PARO, V. H. O currículo do ensino fundamental como tema de política pública: a cultura como conteúdo central. Ensaio: avaliação e políticas públicas em educação. Rio de Janeiro, v. 19, n. 72, p. 485-507, jul./set. 2011.

PINTASSILGO, J. Em torno da arte de ensinar: vocação, paixão, exemplaridade moral e prática. In: PERANDOLES, P. C. (Ed.). Arte y oficio de enseñar: COLOQUIO NACIONAL DE HISTORIA DE LA EDUCACIÓN, 16., 2011. vol. I. El Burgo de Osma: Universidade de Valladolid/Sociedade Española de Historia de la Educación, 2011. p. 201-208.

POSTMAN, N. O desaparecimento da infância. Rio de Janeiro: Graphia, 1999.

POPKEWITZ, T. S. The production of reason and power: curriculum history and intellectual traditions. In: POPKEWITZ, T. S.; PEREYRA, M. A.; FRANKLIN, B. M. Cultural history and education. New York: Routlegdefalmer, 2001. p. 151-183.

PRAIRAT, E. Eduquer e punir. Nancy: Presses Universitaires de Nancy, 1994.

GALLEGO, R. de C. Tempo, temporalidades e ritmos nas escolas primárias públicas em São Paulo: heranças e negociações (1846-1890). 2008. Tese (Doutorado em Educação) - Faculdade de Educação, Universidade de São Paulo, São Paulo, 2008.

SILVA, V. B. Escritos 'modestos' sobre 'grandes auctores': a produção dos manuais pedagógicos no Brasil e em Portugal (1870-1970). In: PERANDOLES, P. C. (Ed.). Arte $y$ oficio de enseñar: COLOQUIO NACIONAL DE HISTORIA DE LA EDUCACIÓN, 16., 2011. vol. II. El Burgo de Osma: Universidade de Valladolid/Sociedade Española de Historia de la Educación, 2011. p. 309-317.

SOARES, M. A linguagem didática. In: NAGLE, J. Educação e linguagem. São Paulo: Edart, 1976. p. 145-160.

SOUZA, R. F. Templos de civilização: a implantação da escola primária graduada no Estado de São Paulo (1890-1910). São Paulo: Unesp, 1998.

TYACK, D.; CUBAN, L. Tinkering toward utopia: a century in public school reform. London: Harvard University Press, 1995.

VALDEMARIN, V. T. Estudando as lições de coisas: análise dos fundamentos filosóficos do Método do Ensino Intuitivo. São Paulo: Fapesp/Autores Associados, 2004.

VARELA, J.; ALVAREZ-URIA, F. A maquinaria escolar. Teoria e Educação, n. 6, p. 68-96, 1992. Porto Alegre: Pannonica.

VIDAL, D. G. Culturas escolares: estudo sobre práticas de leitura e escrita na escola pública primária (Brasil e França, final do século XIX). Campinas: Autores Associados, 2005. 
VIÑAO FRAGO, A. Do espaço escolar e da escola como lugar: propostas e questões. In: FRAGO, A.V.; ESCOLANO, A. Currículo, espaço e subjetividade: a arquitetura como programa. Rio de Janeiro: DP\&A, 1998a. p. 59-139.

VIÑAO FRAGO, A. Tiempos escolares, tiempos sociales: la distribución del tiempo e del trabajo en la enseñanza primaria en España (1838-1936). Barcelona: Ariel, 1998b.

VINCENT, G. L'école primaire française: étude sociologique. Lyon: Presses Universitaires de Lyon/Editions de la Maison des Sciences de l'Homme, 1980.

VINCENT, G. L'éducation prisionniére de la forme scolaire: scolarisatino et socialisation dans les societés industrielles. Lyon: Presses Universitaires de Lyon, 1994.

\section{Bibliografia consultada}

AZANHA, J. M. P. Educação: alguns escritos. São Paulo: Editora Nacional, 1987.

BASTOS, M. H. C. Manuais escolares franceses no Imperial Colégio Pedro II (18561892). História da educação (UFPel), v. 2. p. 39-58, 2008.

BASTOS, M. H. C. Peço a palavra: a politesse dos rituais. Cadernos de Pesquisa. Pensamento Educacional, vol. 3. p. 135-146, 2008.

BASTOS, M. H. C. Aprendendo o labor docente: o Curso Prático de Pedagogia, de Jean-Baptiste Daligault (1851). In: PERANDOLES, Pablo Celada (Ed.). Arte y oficio de enseñar: COLOQUIO NACIONAL DE HISTORIA DE LA EDUCACIÓN, 16., 2011. vol. I. El Burgo de Osma: Universidade de Valladolid/Sociedade Española de Historia de la Educación, 2011. p. 497-505.

BASTOS, M. H. C. Pedagogias e manuais: leituras cruzadas - os manuais de História da Educação adotados no Brasil (1870-1950). BESTANI, R. M.; BRUNETTI, P.; SÁNCHEZ, A. M. M.; FLACHS, M. C. V. de (Orgs.). Textos, autores y bibliotecas: 190 años de la Biblioteca Mayor de la UNC. Córdoba/Argentina: Editora Baez, 2011.

BASTOS, M. H. C. A Revista do Ensino - RS: o novo e o nacional em revista. Pelotas: Seiva, 2005.

BELL, C. Ritual theory, ritual practice. Oxford: Oxford University Press, 2009.

BENCOSTTA, M. L. A. A cultura escolar na historiografia da educação brasileira: alcances e limites de um conceito. In: FELGUEIRAS, M. L.; VIEIRA, C. E. (Orgs.) Cultura escolar, migrações e cidadania. Porto: Sociedade Portuguesa de Ciências da Educação, 2010. p. 33-46.

BENITO, A. E. A escola como cultura: experiência, memória e arqueologia. Campinas: Alínea, 2017.

BITTENCOURT, C. M. F. Livro didático e conhecimento histórico: uma história do saber escolar. Tese (Doutorado em História Social) - Universidade de São Paulo, 1993. 
BLOCH, M. Apologia da História ou o oficio do historiador. Rio de Janeiro: Jorge Zahar, 2001.

BRAUDEL, F. O Mediterrâneo e o mundo mediterrânico. Vol. I. São Paulo: Martins Fontes, 1983.

CAMBI, F. História da pedagogia. São Paulo: Unesp, 1999.

CAMPS, V. Civismo. España: Proteus, 2011.

CÂNDIDO, A. A estrutura da escola. In: PEREIRA, L.; FORACCHI, M. M. Educação e sociedade. São Paulo: Companhia Editora Nacional, 1977, p. 107-128.

CARVALHO, M. M. C. de. A escola e a república. São Paulo: Brasiliense, 1989.

CARVALHO, M. M. C. de. Molde nacional e fôrma cívica: higiene, moral e trabalho no projeto da Associação Brasileira de Educação (1924-1931). Bragança Paulista: EDUSF, 1998.

CATANI, D. B. Educadores à meia-luz: um estudo sobre a Revista do Ensino da Associação Beneficente do Professorado Público de São Paulo. Bragança Paulista: Edusf, 2003.

CATANI, D. B. Educadores à meia-luz: um estudo sobre a Revista de Ensino da Associação Beneficente do Professorado Público de São Paulo 1902-1919. 1989. Tese (Doutorado em Educação) - FEUSP, São Paulo, 1989.

CAVALCANTI, M. J. M. et al. História da educação: vitrais da memória - lugares, imagens e práticas culturais. Fortaleza: Edições UFC, 2008.

CATROGA, F. O republicanismo em Portugal: da formação ao 5 de outubro de 1910 . Coimbra: Faculdade de Letras, 1991.

CATROGA, F. Nação, mito e rito: religião civil e comemoracionismo. Fortaleza: Edições NUDOC/UFC/Museu do Ceará/Secretaria da Cultura do Ceará, 2005.

CATROGA, F. Os passos do homem como restolho do tempo: memória e fim do fim da História. Coimbra: Almedina, 2009.

CHARTIER, A.-M. Fazeres ordinários da classe: uma aposta para a pesquisa e para a formação. Educação e Pesquisa, São Paulo, v. 26, n. 2, p. 157-168, jul./dez. 2000.

CHARTIER, A.-M. Escola, culturas e saberes. In: XAVIER, L. N.; CARVALHO, M. M. C. de; MENDONÇA, A. W; CUNHA, J. L. Escola culturas e saberes. Rio de Janeiro: FGV, 2005. p. 9-28.

CHARTIER, A.-M; HÉBRARD, J. Discours sur la lecture (1880-1980). Paris: Centre George-Pompidou, 1989.

CHARTIER, R. Lectures et lecteurs dans la France d'Ancien Regime. Paris: Seuil, 1987.

CHARTIER, R. Cultura escrita, literatura e história. Porto Alegre: Artmed, 2001.

CHERVEL, A. La culture scolaire: une approche historique. Paris: Belin, 1998. 
CHEVAlLARD, Y. La transposition didactique. Paris: La Pensée Sauvage, 1991.

CUNHA, M. T. S. A escola, os livros e a leitura: à procura daquilo que não se fez esquecer. In: FISCHER, B. T. D. (Org.). Tempos de escola: memórias. São Leopoldo/RS: Oikos Editora, 2011. p.121-132.

CUNHA, M. T. S. Mensageiro de sociabilidades: estudos sobre um jornal escolar infantil (1946-1952). In: MORGA, A. E. (Org.). História, cidade e sociabilidades. Itajaí: Casa Aberta Editora, 2011. p.235-250.

CUNHA, M. T. S. Ser de Cerimônia: manuais de civilidade e a construção de sujeitos históricos (1920-1960). In: NEPONUCEMO, M. de A.; TIBALLI, E. F. A. (Orgs.). A educação e seus sujeitos na História. Belo Horizonte: Argvmentvm, 2007. p.91-107.

DURKHEIM, É. A educação como processo socializador: função homogeneizadora e função diferenciadora. In: PEREIRA, L.; FORACCHI, M. M. Educação e sociedade. 8. ed. São Paulo: Companhia Editora Nacional, 1977.

ELIAS, N. La dynamique de l'Occident. Paris: Calmann-Lvy, 1975.

ELIAS, N. A sociedade de corte. Tradução Ana Maria Alves. Lisboa: Editorial Estampa, 1987.

FARIA FILHO, L. M. Cultura escolar e cultura urbana: perspectivas de pesquisa em história da educação. In: XAVIER, L. N.; CARVALHO, M. M. C.; MENDONÇA, A. W.; CUNHA, J. L. (Orgs.). Escola, cultura e saberes. Rio de Janeiro: Editora FGV, 2005. p. 29-37.

FARIA FILHO, L.; VIDAL, D. G. Os tempos e os espaços escolares no processo de institucionalização da escola primária no Brasil. Revista Brasileira de Educação, ANPED, n. 14,2000 .

GALLEGO, R. de C. A configuração temporal e as inovações nos modos de ensinar e aprender nas escolas públicas primárias (São Paulo, Brasil - 1850 a 1890). In: PERANDOLES, P. C. (Ed.). Arte y oficio de enseñar. Dos siglos de perspectiva histórica. COLOQUIO NACIONAL DE HISTORIA DE LA EDUCACIÓN, 16., 2011. El Burgo de Osma: Sociedad Española de Historia de la Educación/Universidad de Valladolid/ Centro Internacional de la cultura escolar, 2011. p. 117-125.

GALVÃO, A. M. de O. A palmatória era a sua vara de condão: práticas escolares na Paraíba (1890-1920). In: FARIA FILHO, L. M. (Org.). Modos de ler/Formas de escrever: estudos de história da leitura e da escrita no Brasil. Belo Horizonte: Autêntica, 1998. p. 117-142.

GÉLIS, J. A individualização da criança. In: ARIÈS, P.; DUBY, G. História da vida privada: da Renascença ao Século das Luzes. Volume III. São Paulo: Companhia das Letras, 1991.

GONDRA, J. G. Artes de civilizar: medicina, higiene e educação escolar na Corte imperial. Rio de Janeiro: Eduerj, 2004. 
GRAFF, H. Os labirintos da alfabetização: reflexões sobre o passado e o presente da alfabetização. Porto Alegre: Artes Médicas, 1994.

HAMILTON, D. Notes from nowhere (on the beginning of modern schooling). In: POPKEWITZ, T. S.; PEREYRA, M. A.; FRANKLIN, B. M. Cultural history and education. New York: Routlegdefalmer, 2001. p. 187-206.

HUIZINGA, J. Homo ludens. 4. ed. São Paulo: Perspectiva, 1999.

LIMA, A. L. G. O espectro da irregularidade ronda o aluno: um estudo da literatura pedagógica e da legislação sobre a 'criança-problema'. 2004. Tese (Doutorado) - Faculdade de Educação da USP, São Paulo, 2004.

LOPES, E. M. T.; FARIA FILHO, L. M.; VEIGA, C. G. 500 anos de educação no Brasil. Belo Horizonte: Autêntica, 2000.

MCLAREN, P. Rituais na escola: em direção a uma economia política de símbolos e gestos na educação. Petrópolis: Vozes, 1992.

MANNHEIM, K.; STEWART, W. A. C. O subgrupo de ensino. In: PEREIRA, L.; FORACCHI, M. M. Educação e sociedade. 8. ed. São Paulo: Companhia Editora Nacional, 1977. p. 129-137.

MARANGON, A. C. R. Crianças e alunos em sala de aula: a circulação do debate sobre métodos de ensino em Portugal e no Brasil (1930-1940). 2011. Tese (Doutorado) - Faculdade de Educação da Universidade de São Paulo, 2011.

MATHIESON, L. C. Conversas sobre ler e escrever: alfabetização e cultura escolar na Revista de Ensino (1902-1910). 2009. Trabalho Complementar de Curso (Educação) Faculdade de Educação da Universidade de São Paulo, 2009.

MONARCHA, C. Escola Normal da Praça: o lado noturno das luzes. 3. reimpressão. Campinas: Editora da Unicamp, 1999.

MOSCOVICI, S. La psicanalyse, son image et son public. Paris: Presses Universitaires de France, 1961.

NAGLE, J. Discurso pedagógico: uma introdução. In: NAGLE, J. Educação e linguagem. São Paulo: Edart, 1976. p. 11-42.

PEREZ, T. T. História da formação de professores em São Paulo (1875-1894): intersecção entre os ideais de professor e de escola. 2012. Dissertação (Mestrado) - Faculdade de Educação da Universidade de São Paulo, 2012.

PETERS, R. S. A educação como iniciação. In: ARCHAMBAULD, R. D. Educação e análise filosófica. São Paulo: Saraiva, 1979.

PETITAT, A. Produção de escola/ produção de sociedade. Porto Alegre: Artes Médicas, 1994.

PINTASSILGO, J.; COSTA, R. A. A construção histórica do tempo escolar em Portugal (do final do século XIX às primeiras décadas do século XX). Repositório da Universi- 
dade de Lisboa. Disponível em: <http://repositorio.ul.pt/handle/10451/4011>. Acesso em: 15 jan. 2018.

POPKEWITZ, T. S.; PEREYRA, M. A.; FRANKLIN, B. M. History, the problem of knowledge and the New Cultural History of Schooling. In: POPKEWITZ, T. S.; PEREYRA, M. A.; FRANKLIN, B. M. Cultural history and education. New York: Routlegdefalmer, 2001. p. 3-42.

REVEL, J. Os usos da civilidade. In: ARIÈS, P.; DUBY, G. História da vida privada: da Renascença ao Século das Luzes. Trad.: Hildegard Feist. São Paulo: Companhia das Letras, 1991. p. 169-209.

RIBEIRO, R. J. A etiqueta no Antigo Regime. 3. ed. São Paulo: Brasiliense, 1990.

SNYDERS, G. La joie à l'école. Paris: Presses Universitaires de France, 1986.

SOARES, M. Linguagem e escola: uma perspectiva social. São Paulo: Ática, 1986.

SOUZA, R. F. Espaço da educação e da civilização: origens dos Grupos Escolares do Brasil. In: SOUZA, R. F.; VALDEMARIN, V. T.; ALMEIDA, J. S. O legado educacional do século XIX. Araraquara: UNESP/FCL, 1998. p.19-62.

STEPHANOU, M. Tratar e educar: discursos médicos nas primeiras décadas do século XX. 1999. Tese (Doutorado) - UFRGS, Porto Alegre, 1999. [mimeo].

STEPHANOU, M. Qualis pater, talis filius? Educação, cognição e saberes médicos nas primeiras décadas do século XX. In: VASCONCELOS, M. L. M. C. (Org.). Educação e história da cultura: fronteiras. São Paulo: Mackenzie, 2002.

STEPHANOU, M. Bem viver em regras: urbanidade e civilidade em manuais de saúde. Educação Unisinos, v. 4, p. 35-44, 2006.

TERRIN, A. N. O rito: antropologia e fenomenologia da ritualidade. São Paulo: Paulus, 2004.

TREVISAN, T. História da disciplina Pedagogia nas Escolas Normais do Estado de São Paulo (1874-1959). 2011. Tese (Doutorado) - Faculdade de Filosofia e Ciências, Universidade Estadual Paulista (UNESP), Marília, 2011.

VALDEMARIN, V. T. História dos métodos e materiais de ensino: a escola nova e seus modos de uso. São Paulo: Cortez, 2010.

VEIGA, C. G. A escolarização como projeto de civilização. Revista Brasileira de Educação, n. 21, p. 90-103, dez. 2002.

VIDAL, D. G. O exercício disciplinado do olhar: livros, leituras e práticas de formação docente no Instituto de Educação do Distrito Federal (1932-1937). 1995. Tese (Doutorado) - Faculdade de Educação da Universidade de São Paulo, São Paulo, 1995.

VIDAL, D. G. Livros por toda parte: o ensino ativo e a racionalização da leitura nos anos 1920 e 1930 no Brasil. In: ABREU, M. (Org.). Leitura, história e história da leitura. Campinas: Mercado de Letras/Associação de Leitura do Brasil/Fapesp, 1999. p. 335-355. 
VIDAL, D. G. Escola Nova e processo educativo. In: LOPES, E. M. T.; FARIA FILHO, L. M.; VEIGA, C. G. 500 anos de educação no Brasil. Belo Horizonte: Autêntica, 2000. p. 497-517.

VIÑAO FRAGO, A. History of education and cultural history: possibilities, problems, questions. In: POPKEWITZ, T. S.; PEREYRA, M. A.; FRANKLIN, B. M. Cultural history and education. New York: Routlegdefalmer, 2001. p. 125-150.

WARDE, M. J.; CARVALHO, M. M. C. Politics and culture in the making of History of Education in Brazil. In: POPKEWITZ, T. S.; PEREYRA, M. A.; FRANKLIN, B. M. Cultural history and education. New York: Routlegdefalmer, 2001. p.83-104.

WARDE, M. J.; CARVALHO, M. M. C. Política e cultura na produção da história da educação no Brasil. In: WARDE, M. J. (Org.). Contemporaneidade e Educação: revista semestral temática de ciências sociais e educação, Ano V, n. 7, p. 9-33, 2000/1 ${ }^{\circ} \mathrm{sem}$. Rio de Janeiro: Instituto de Estudos da Cultura e Educação Continuada.

XAVIER, L. N.; CARVALHO, M. M. C.; MENDONÇA, A. W.; CUNHA, J. L. (Orgs.). Escola, cultura e saberes. Rio de Janeiro: Editora FGV, 2005. p. 9-28.

\section{Fontes}

AFFREIXO, J. M. da G.; FREIRE, H. Elementos de Pedagogia para servirem de guia aos candidatos ao magistério primário. 5. ed. Lisboa: Livraria Ferreira, 1879.

ANAQUIM, C. M. Compendio de moral e doutrina christã. Lisboa: Livraria Ferreira, 1906.

ANJO, C. Crianças tímidas e apáticas. Revista Escolar, ano 3, n. 3, p. 82-83, março 1923.

BASTOS, António. Grammática intuitiva da língua portuguesa. Porto: Livraria Editora de Antonio Figueirinhas, 1901.

BITTENCOURT, F. P. Compendio de pedagogia escolar. Rio de Janeiro: Livraria Francisco Alves, 1908.

BOMFIM, M. Lições de pedagogia: theoria e pratica da educação. 2. ed. Rio de Janeiro: Francisco Alves, 1920.

COELHO, J. A. Manual pratico de pedagogia para uso dos professores em geral e em especial dos professores de Ensino Médio e Primario. Porto: Livraria Editora de José Figueirinhas Junior, s.d.

COELHO, J. A. Noções de pedagogia elementar. 2. ed. Lisboa: Empreza da História de Portugal, 1907.

CORREIA, V. O ensino e a educação em Portugal. Lisboa: Livraria Clássica Editora, 1907. 
EDUCAÇÃO Nacional: supplemento - discussões pedagógicas e exercícios práticos, $\mathrm{n}$. 1, domingo 1 de outubro de 1899.

EDUCAÇÃO Nacional: supplemento - discussões pedagógicas e exercícios práticos, n. 9, domingo 3 de junho de 1900.

A ESCOLA publicação semana para creanças. São Manoel do Paraizo. Anno I, n. 1, p. 5-6, 14 de fevereiro de 1904.

FEITOSA, M. A. Duas palavras sobre o ensino. São Paulo: Typ. de Vanorden \& Cia., 1892.

LEITÃO, A. Elementos de Pedagogia em harmonia com os programas das Escolas Normais. 6. ed. Coimbra: França e Armenio Livreiros-Editores, 1916.

PASSALAQUA, C. Pedagogia e methodologia (theorica e prática). São Paulo: Typographia a Vapor de Jorge Seckler \& Companhia, 1887.

Texto recebido em 18 de fevereiro de 2018.

Texto aprovado em 20 de março de 2018. 